\title{
Implementation of Online Promethee Method for Poor Family Change Rate Calculation
}

\author{
Dhady Lukito Aji ${ }^{1, *}$, Suryono Suryono ${ }^{1,2}$, Catur Edi Widodo ${ }^{1,2}$ \\ ${ }^{1}$ Master of Information System, School of Post-Graduate Studies, Diponegoro University, Semarang, Indonesia \\ ${ }^{2}$ Departement of Physics, Faculty of Science and Mathematic, Diponegoro University, Semarang, Indonesia
}

\begin{abstract}
This research has been done online calculation of the rate of poor family change rate by using Preference Ranking Method of Organization Of Enrichment Evaluation (PROMETHEE) .This system is very useful to monitor poverty in a region as well as for administrative services related to poverty rate. The system consists of computer clients and servers connected via the internet network. Poor family residence data obtained from the government. In addition, survey data are inputted through the client computer in each administrative village and also 23 criteria of input in accordance with the established government. The PROMETHEE method is used to evaluate the value of poverty and its weight is used to determine poverty status. PROMETHEE output can also be used to rank the poverty of the registered population of the server based on the netflow value. The poverty rate is calculated based on the current poverty rate compared to the previous poverty rate. The rate results can be viewed online and real time on the server through numbers and graphs. From the test results can be seen that the system can classify poverty status, calculate the poverty rate change rate and can determine the value and poverty ranking of each population.
\end{abstract}

\section{Preface}

Poverty is a term used to denote absolute poverty wherein a person experiences a very hard life due to difficulties to meet their basic needs such as food, clothes, shelter and education [1]. The rate numbers of poverty according to the Regional Development Planning Agency (BAPPEDA) is the data rate of poor people who are in the process of monitoring the number of poverty to know the impact of Poverty alleviation and social assistance programs to reduce the number of poor families. Planning in poverty alleviation strategies and social assistance budget allocations requires a rate of change in a city to see the level of success and achievement of program objectives with valid data.

Method of Preference Ranking Organization Method for Enrichment Evaluations (abbreviated as PROMETHEE) online based is used to validate the proposed data of insufficient information application used by government in the city poverty data collection before doing the calculation of poverty rate change. Based on the test results, it can be seen that the system can classify poverty status, calculate the poverty rate change rate and can determine the value and poverty ranking of each population. The rate results can be viewed online and real time in the form of numbers and graphics on http://lajukemiskinankotasemarang.info page.

The PROMETHEE method is a well-known method and has many separate criteria [2]. The PROMETHEE method was first developed by Brans and published in
1982 at a conference hosted by Nadeau and Landry at the University of Laval, Quebec, Canada [3]. The PROMETHEE method is not only applicable for ranking but can also be used to evaluate the feasibility of program execution by determining its net flow number which can not be found in other methods. If a ranking is using PROMETHEE net flow results positive, then a new object deserves to be called good data. Conversely, if the net flow is negative, it is called unfavorable data. The example of using PROMETHEE method is that the method can be used in employee selection process at a company. Experts from the company are appointed to determine the company's required quality of criteria, the value obtained, then normalized and determining attributes. For negative net flow, the value is ignored and will not be processed at the next calculation. The results of the PROMETHEE process on the required quality of the existing criteria are then set as the best criterion alternative [4].

The use of the PROMETHEE method can be used in the selection of industrial equipment. The labor, materials, and equipment that will be used in the production process is a very important component in the production system. The used equipment is an important subject that greatly affects efficiency system, work effectiveness, and quality of product. Some mistakes in selecting equipment may have a negative effect on the production system [5]. The PROMETHEE method can be used to predict the bankruptcy of an institution based on harmony and discrepancy between the members of the organization. Relationships pattern between members

* Corresponding author: dhadylukitoaji@gmail.com 
can be used as a reference in making measurements and calculations [6]. The PROMETHEE method can be used to measure the performance quality of a school. By looking at achievements, student absenteeism, social activities and project criteria, the method can show that Junior High School performs better than senior high schools and schools in the cities are better performing than the village schools. There was also a strong relationship between attainment and absenteeism [7]. Comparison between PROMETHEE method and AHP method in selecting building structure system, and the result PROMETHEE were chosen as the right method to evaluate alternative solution in the process of building structural system selection. The PROMETHEE method is more consistent, easy to understand, and requires less interaction with decision makers. Linearity and other assumptions for preference functions can be accepted by the decision maker. By utilizing the PROMETHEE Method in analyzing a thing, the most effective criteria in the decision-making process can be determined. This is a unique feature of PROMETHEE that is not available in AHP, or other MCDM techniques such as the Elimination Et Choix Tradiniant la Realité (ELECTRE) and TOPSIS methods [7].

The rate of changed numbers calculation is an analysis technique that calculates the percentage change of the amount of data of an object from period to period obtained by way of survey so that the data can be observed trends or patterns of change for use in evaluation and input in making decision for a problem. The calculation of the rate change rate is the main input in the final conclusion to fill in the monitoring instrument and evaluation of the benefits of a program. The example of using the rate change calculation that the calculation can be used in the Evaluation of Program Benefits in Tourism Affairs in a city. The rate of change in the number of tourist arrivals in 2005 - 2008 was calculated at the rate of change of numbers and used as the input to fill monitoring instruments by the government [8].

\section{Method}

\subsection{Materials and Research Tools}

This study requires data based on the criteria. The survey data were obtained from questionnaires filled out by residents who proposed the Certificate of Poor (SKTM). The criteria used are relevant criteria based on Mayor Regulation on indicators, criteria and classification of urban poor. While the sub criteria, the value of the scale of each criterion is obtained from the interview to the Regional Development Planning Agency. The used tools are a set of client computers and servers and PHP software.

\subsection{Architecture Network}

This software will be used by two categories of users, namely Regional Development Planning Agency data center as server and urban village administrator as client.
The proposed architecture network is a network connected to the internet and both computer servers and clients must have internet access in order to be connected to each other. The client-server system is the best system to use, the system is capable of generating robust database applications in terms of securities, as well as reducing network traffic density [9]. The architecture network is shown in Figure 1.

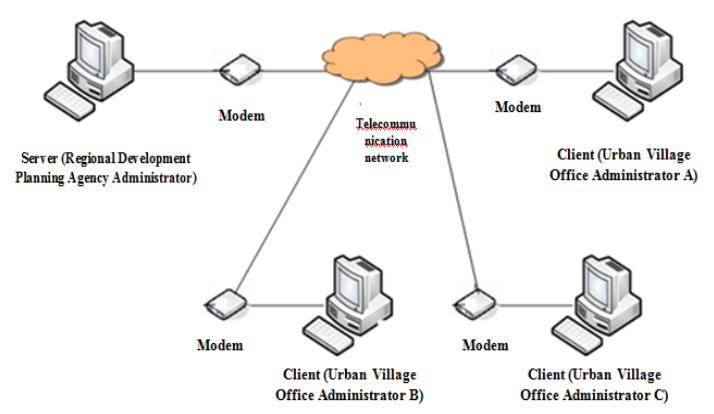

Fig. 1. Architecture network

\subsection{Access Rights}

In this system, there are two different access rights namely Regional Development Planning Agency data center as server and urban village administrator as client. The server has facilities to access the application form, user form, criteria form, family card form, application form of poor certificate, PROMETHEE forms, resident status report forms, poor certificate application forms, and poverty rate reporting forms. Meanwhile urban village administrator as client only has facility to access letter application form of poor certificate, PROMETHEE forms, resident status report forms, poor certificate entry application forms, and poverty rate reporting forms. The access rights above are shown in the use case shown in Figure 2 .

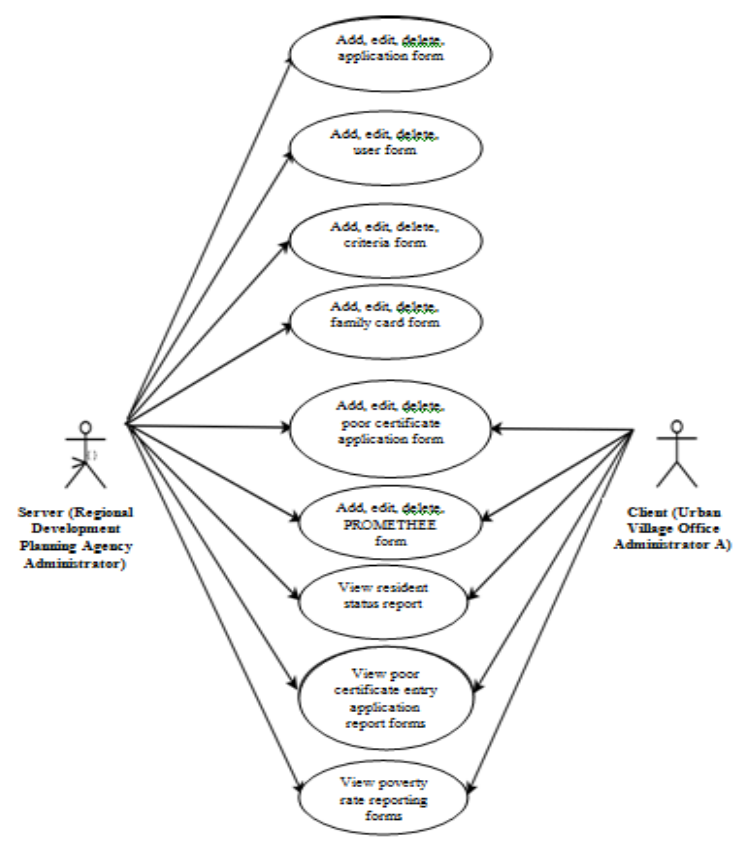

Fig. 2. Use case access rights 


\subsection{PROMETHEE Modeling}

The use of the PROMETHEE model is accomplished by the following steps:

\section{Step 1}

Determine criteria and subcriteria.

The criteria used are 6 criteria, namely food, house, clothing, education, health, income and asset ownership. While the sub criteria is taken from the questionnaire questionnaires filled out by the poor applicants as many as 23 sub criteria such as how many times consuming the staple food in a day, the frequency of eating meat and or eggs eaten by the family in a week, the status of the house inhabited today, The floor of the house inhabited today, the type of floor of the house, the type of wall of the house, the availability of electricity, the average number of new clothes that can be purchased by the family in the latest year, whether each family member has different clothes for at home / work / school / travel, able to finance the family's education to what level, is there any family member who dropped out of school, if there is a sick family brought to primary health care, if there is family member Sick and require advanced health care / hospital, who finances him/her, whether family or family members are active smokers, if taken to health care facilities, to whom you do the treatment, whether there are family members who have disability (physical / mental), Availability of clean water, availability of toilet room, household income source, employment status of head of household, number of family member working, occupation of head of household, number of family member, amount of family income per month, and whether owning productive asset.

\section{Step 2}

Determine the value of the alternative.

The determination of the value of the alternative is obtained from questionnaires that are based on the criteria and scale that have been predetermined and filled by the applicant of Poor Certificate (SKTM) and submitted to the kelurahan. This calculation using the minimization and the weight ratio are equally important.

\section{Step 3}

Selection and calculation of preference values.

There are six forms of preference function in the Promethee, namely Type I or Usual Criterion, Type II or QuasiCriterion, Type III or Criteria with Linear Preferences, Type IV or Level Criterion, Type V or Criteria With Linear and Unbound Area and Type VI or Gaussian Criterion. The Usage of Usual Criterion is particularly suitable for equal importance of qualitative criteria. Examples of cases of usual criteria usage are yes / no answers or answers that have range of 0-5 [4]. The counter is using the equation as follow:

\section{Usual Criterion}

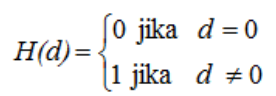

Notes :

1. $H(d)$ : Function of cross-alternative differences

2. $\mathrm{d}$ : Difference in criterion value $\{\mathrm{d}=\mathrm{f}(\mathrm{a})-\mathrm{f}(\mathrm{b})\}$

Function $\mathrm{H}(\mathrm{d})$ for this preference function is shown in Figure 3

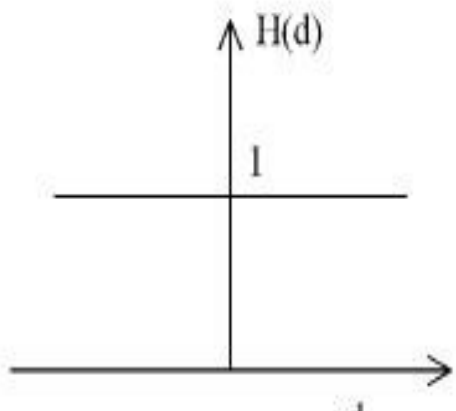

d

Fig.3. Usual Criterion [4]

\section{Step 4}

The calculation of preference index value.

The Calculation of Preference Index Value is a preference measure from one alternative into another, the closer to 1 (one), the greater the preference be. Therefore, the preference index is the intensity of the decision maker's preference which states that the other alternatives with simultaneous consideration of all criteria. The counter is using the equation as follow:

Preference Index Value

$$
\wp(a, b)=\frac{1}{n} \sum_{i=1}^{n} P_{i}(a, b)
$$

with

$\wp(a, b)$ Shows an $a$ alternative preference index is better than $b$ alternative

$P_{i}(a, b)$ Is an $a$ alternative preference to $b$ alternative

$\mathrm{n} \quad$ Is the number of criteria

$\underline{\text { Step } 5}$ : Calculating the value of leaving flow and entering flow.

The calculation of the value of leaving flow $(\Phi+)$, entering flow $(\Phi-)$ is the process of determining the priority relationship between one alternatives to others'. the counter is using the equation as follow:

Leaving Flow

$$
\phi^{+}(\mathrm{a})=\frac{1}{n-1} \sum_{x \in A} \mathrm{p}(\mathrm{a}, \mathrm{x})
$$

Entering Flow

$$
\Phi^{-}(\mathrm{a})=\frac{1}{n-1} \sum_{x \in A} \mathrm{p}(\mathrm{x}, \mathrm{a})
$$

with

$\Phi^{+}$(a) is Leaving Flow a alternative 
$\Phi$ (a) is Entering Flow a alternative

$\mathrm{p}(\mathrm{a}, \mathrm{x})$ is the number of criteriais showing alternative preferences a more than $\mathrm{x}$.

$\mathrm{n}$ is the number of criteria

\section{Step 6}

Net flow calculation.

Net flow calculation $(\Phi)$ is done by determining the differences of Leaving Flow and Entering Flow value and the result is dominance value of each alternative. If the netflow result is positive, then a new object can to be called as good data. For negative netflow, the value is ignored and will not be processed at the next calculation. The higher the netflow value, the higher the rank be.

The determination is using the equation as follow:

Net flow

$$
\Phi(\mathrm{a})=\Phi^{+}(\mathrm{a})-\Phi^{-}(\mathrm{a})
$$

With

$\Phi$ (a) is Net Flow a alternative

$\Phi^{+}$(a) is Leaving Flow a alternative

$\Phi^{-}$(a) is Entering Flow a alternative

\subsection{The Rate Of Changed Numbers Calculation}

The rate of changed numbers calculation is an analysis technique that calculates the percentage change of the number of an object which is observed by using time series data obtained by survey. The determination is using the equation as follow:

The rate of changed numbers calculation

$$
P=\frac{A_{t n}-A_{0-}}{A_{t o}} \times 100 \%
$$

with

$\mathrm{P}$ is the percentage change in the number of alternative

$A$ is the Number of alternative

tn is the current month

to was the last month

\section{Results and Discussion}

Stages of web based calculation of the poverty rate are done by doing with the following stages:

a. Data Retrieval

The data used are data from Regional Development Planning Agency in January - June 2016 a number of 150 Heads of Families include 350 residents. Out of 150 Heads of Families, 60 heads of families signed up for SKTM/Poor Certificate. While the manual calculation took 5 data of the heads of the families that is Family 1, Family 2, Family 3, Family 4, Family 5 . The 5 th family signed himself up for Poor Certificate.

b. Verification of poverty status data will be done by following steps :
The first step is to determine the value of alternatives. The determination of the value of the alternative is obtained from the questionnaire based on the criteria and scale that has been predetermined and filled by Poor Certificate and submitted to the urban village office. This calculation is using the minimization and weight ratio which are equally important.

The second step is the determination of criteria preference. In this study, the use of the usual criterion preference is very suitable to use. Because it is having the same important weight and the answer is yes / no and the answer is using a 0-5 choice scale.

The Third Step is the Calculation of Preference Index Value is a preference measure of one alternative to another, the closer to 1 (one), the greater the preference be. Thus, the preference index is the intensity of the decision maker's preference which states that the other alternatives are simultaneously consideration of all rituals. This calculation uses the usual criteria where the preference value is 0 if the difference between alternatives results 0 or less than 0 and the preference value is 1 if the difference between the alternatives is more than 1 . The counter on the dashboard system showed in figure 4 .

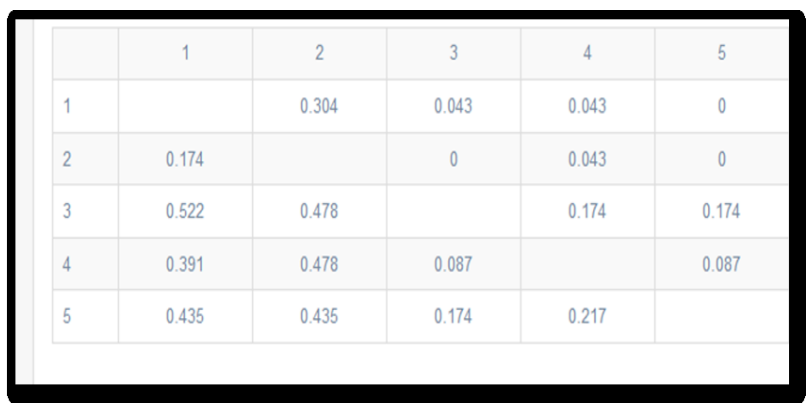

Fig. 4. Dashboard view of the preference index value

The view on the dashboard of preference index values is then verified by counting the manual preference index. Manual counter results are compared with the dashboard preference index table as shown in table 1.

Table 1. Manual Preference Index Verification

\begin{tabular}{|c|c|c|c|c|c|c|c|}
\hline & Family1 & Family2 & Family3 & Family4 & Family5 & amount & verivication result \\
\hline Family1 & & 0.304 & 0.043 & 0.043 & 0.000 & 0.391 & consistent \\
\hline Family2 & 0.174 & & 0.000 & 0.043 & 0.000 & 0.217 & consistent \\
\hline Family3 & 0.522 & 0.478 & & 0.174 & 0.174 & 1.348 & consistent \\
\hline Family4 & 0.391 & 0.478 & 0.087 & & 0.087 & 1.043 & consistent \\
\hline Family5 & 0.435 & 0.435 & 0.174 & 0.217 & & 1.261 & consistent \\
\hline amount & 1.522 & 1.391 & 0.261 & 0.435 & 0.261 & & consistent \\
\hline verivication result & consistent & consistent & consistent & consistent & consistent & consistent & \\
\hline
\end{tabular}

The fourth step is the calculation of the value of leaving flow $(\Phi+)$ and entering flow $(\Phi-)$. Arrangement of this domination relationship is the process of determining the priority relationship between one alternative to another. At this stage, the calculation steps consist of Leaving flow $(\Phi+)$ calculation which means the greater the value, the more dominance an alternative 
to other alternatives will be and the calculation of Entering flow ( $\Phi-)$ where the smaller the value is, the more dominance an alternative to other alternatives will be. The counter on the dashboard is shown in figure 5 .

\begin{tabular}{|l|c|c|c|c|}
\hline NAMA & LEAVING FLOW & RANK & ENTERING FLOW & RANK \\
\hline NAME & 0.098 & 4 & 0.381 & 2 \\
\hline 2 & 0.054 & 5 & 0.424 & 1 \\
\hline 3 & 0.337 & 1 & 0.076 & 4 \\
\hline 4 & 0.261 & 3 & 0.119 & 3 \\
\hline 5 & 0.315 & 2 & 0.065 & 5 \\
\hline
\end{tabular}

Fig. 5. The dashboard calculation view leaving flow and entering flow

Views on the dashboard leaving flow and entering flow value then the results are verified by performing manual calculations. The manual counter results are compared to the table leaving flow and entering flow dashboard as shown in table 2 and table 3.

Table 2. Manual Leaving Flow Verification

\begin{tabular}{|c|c|c|c|c|c|}
\hline Name & \multicolumn{3}{|l|}{ Counter of Leaving Flow } & Rank & Verivication \\
\hline Family 1 & \begin{tabular}{|l} 
1/(5-1)* \\
(Family 1,Family 2)+(Family 1,Family 3)+ \\
(Family 1,Family 4)+(Family 1,Family 5))
\end{tabular} & $1 / 4 * 0.391=$ & $=0.098$ & 2 & consistent \\
\hline Family 2 & \begin{tabular}{|l}
$1 /(5-1)^{*}$ \\
(Family 2,Family 1)+(Family 2,Family 5$)$ \\
$+($ Family 2 ,Family 4$)+($ Family 2 ,Family 3$))$
\end{tabular} & $1 / 4 * 0.217=$ & $=0.054$ & 1 & consistent \\
\hline Family 3 & $\begin{array}{l}1 /(5-1)^{*} \\
(\text { (Family 3,Family 1)+(Family 3,Family } 5) \\
+(\text { Family 3,Family } 4)+(\text { Family 3,Family 2)) }\end{array}$ & $1 / 4 * 1.348=$ & $=0.337$ & 4 & consistent \\
\hline Family 4 & \begin{tabular}{|l|}
$/(5-1)^{*}$ \\
$($ (Family 4,Family 1)+(Family 4,Family 5$)$ \\
$+($ Family 4,Family 3)+(Family 4,Family 2)) \\
\end{tabular} & $1 / 4 * 1.043=$ & $=0.261$ & 3 & consistent \\
\hline Family 5 & $\begin{array}{l}1 /(5-1)^{*} \\
(\text { (Family } 5, \text { Family } 1)+(\text { Family } 5, \text { Family } 4) \\
+(\text { Family } 5, \text { Family } 3)+(\text { Family } 5, \text { Family } 2))\end{array}$ & $1 / 4 * 1.261=$ & $=0.315$ & 5 & consistent \\
\hline
\end{tabular}

Table 3. Manual Entering Flow Verivication

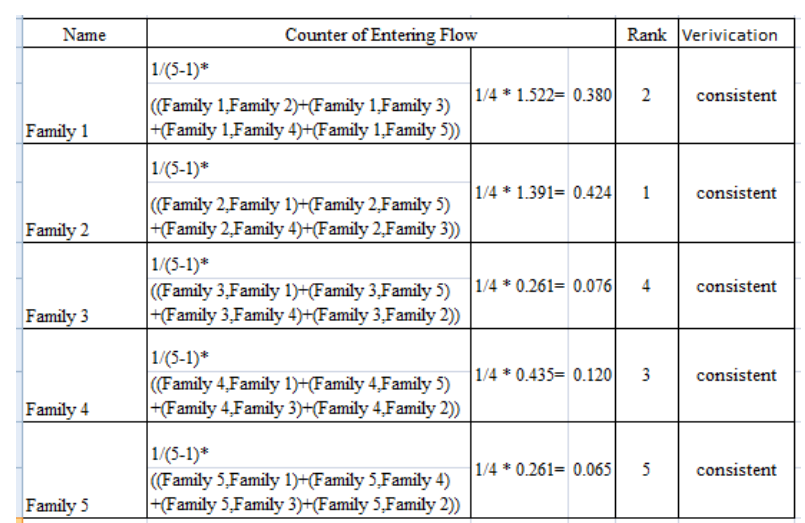

The fifth step is to calculate the Net flow $(\Phi)$. Net flow calculation $(\Phi)$ Is the difference between Leaving Flow and Entering Flow value and the result is the dominance value for each alternative. If the net flow result is positive, then a new object deserves to be called good data. Evaluation and ranking are done by selecting the net flow result data. If the net flow result is positive, then a new object deserves to be called good data. In this case a family with a positive net flow can be called a poor family which is eligible to be given poor certificate. Conversely, if the family has a negative net flow then it is called a non-poor family that is not worthy to be given poor certificate. In the case of poor families, only families with positive net flow can be included in the rank, while families with negative net flow are not included in the rank. The higher the value of net flow, the poor of a family be. Which means the higher rank, they will get as shown in figure 6 .

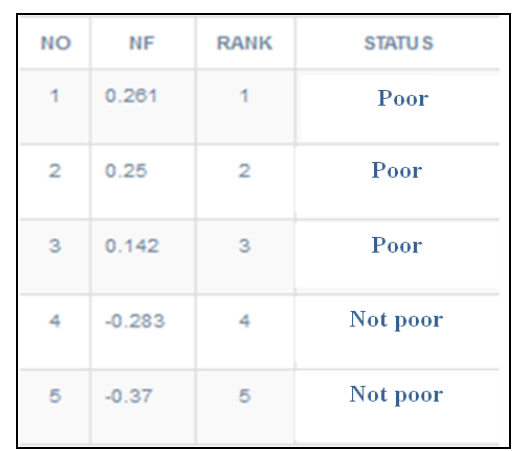

Fig. 6. Netflow calculation dashboard view

After the PROMETHEE method is verified by manual counting, the numbers, rank and status appearing on the system and the manual numbers will be the same. Then the system can be said that it runs well and can be used to process data with a larger amount and then calculated its poverty rate. At this stage, it is using data from Regional Development Planning Agency in January June 2016 a number of 150 heads of families include 350 residents. Out of 150 Heads of Families, 60 heads of household signed up for Poor Certificate. The applicants were evaluated using the PROMETHEE method and resulted in only 44 families who could be declared poor. 16 The rest are not eligible to be called poor families. the number of 44 heads of households, are further explained that the total population in which the male sex are poor as many as 71 people and the number of female population including the poor as many as 60 people.

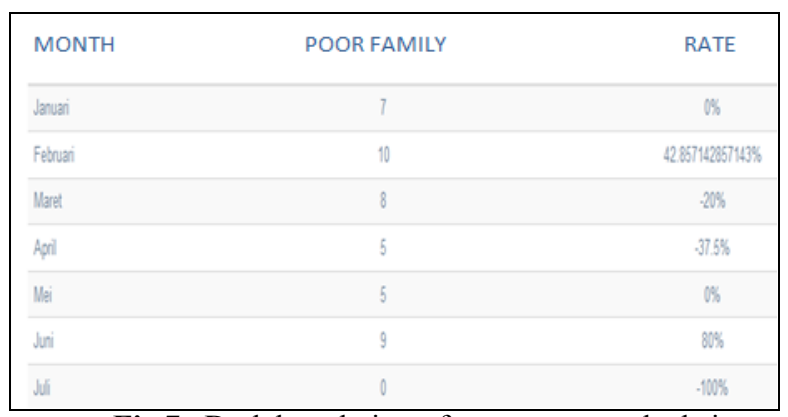

Fig.7. Dash board view of poverty rate calculation

The sixth step is the calculation of the poverty rate change. This calculation is done by using data that have been evaluated and declared as poor family for 6 month, 
then counted the percentage change of poverty number from one month to other months. The poverty table count results on the system dashboard as shown in Figure 7.

The display on the dashboard calculates the rate of poverty then the results derived. The results of manual count are compared to the dashboard view of poverty rate calculation as shown in Table 4.

Table 4. Calculation of Percentage of poverty rate

\begin{tabular}{|c|c|c|c|c|c|}
\hline Month & Poor Family & \multicolumn{2}{|l|}{ Counter } & RATE & Verivication \\
\hline Januari & 7 & $\begin{array}{l}\text { =poor family amount Januari-poor family } \\
\text { amount before/poor family amount before }\end{array}$ & $=(7-0) / 0^{*} 100 \%$ & $0 \%$ & Consistent \\
\hline Februari & 10 & $\begin{array}{c}\text { =poor family amount Februari-poor family } \\
\text { amount Januari/Julah KK Januari }\end{array}$ & $=(10-7) / 7^{*} 100 \%$ & $42.86 \%$ & Sesuai \\
\hline Maret & 8 & $\begin{array}{c}\text { =poor family amount Maret-poor family } \\
\text { amount Februari/poor family amount } \\
\text { Februari }\end{array}$ & $=(8-10) / 10 * 100 \%$ & $-20 \%$ & Sesuai \\
\hline April & 5 & $\begin{array}{l}\text { =poor family amount April-poor family } \\
\text { amount Maret/poor family amount Maret }\end{array}$ & $=(5-8) / 8^{*} 100 \%$ & $-37.50 \%$ & Sesuai \\
\hline Mei & 5 & $\begin{array}{l}\text { =poor family amount Mei-poor family } \\
\text { amount April/poor family amount April }\end{array}$ & $=(5-5) / 5^{*} 100 \%$ & $0 \%$ & Sesuai \\
\hline Juni & 9 & $\begin{array}{l}\text { =poor family amount Juni-poor family } \\
\text { amount Mei/Julah KK Mei }\end{array}$ & $=(9-5) / 5^{*} 100 \%$ & $80 \%$ & Sesuai \\
\hline
\end{tabular}

From the poverty rate calculation data above, the figures are then shown in graphical form as shown in Figure 8 .

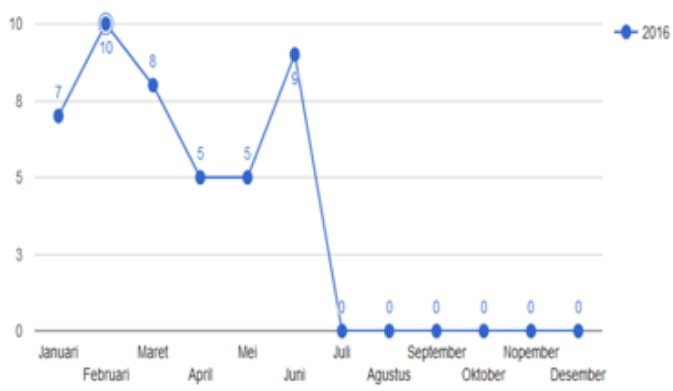

Fig. 8. Poverty rate

\section{Conclusions}

Based on the results of research and discussion on the system of calculating the poverty rate change, it results some conclusions that the system of calculating the poverty rate change rate, can evaluate the feasibility of determining the status of poverty. Out of the 60 residents who signed up for the granting of Poor Certificate, 16 were declared to be poor. The poverty rate change calculation system can also provide a percentage of poverty rate change data per month. The given percentage of rate poverty change data can be used for monitoring poverty rates. The development of a poverty rate, web-based poverty rate, the evaluation system, alternative rankings, and poverty percentages can be viewed online and in real time so that decisions can be made quickly and accurately.

\section{References}

1. B. Ikejiaku, Journal of Sustainable Development (2009)

2. S. Vinodh, and R.J. Girubha., Applied Mathematical Modelling 36, 5301-5308 (2012)

3. M. Behzadian, R.B. Kazemzadeb, A. Albadvi, M. Aghdasi, European Journal of Operational Research 200, 198-215 (2010)

4. T. Dereli, A. Durmusoglu, S.U. Seckiner, and N. Avlanmaz, An OfficialTurkis Fuzzy System Association, Vol.1,No 2.,pp. 126-140 (2010)

5. B. Yilmaz, and M. Dagdeviren, Expert Systems with Applicatications 38, 11641-11650. (2011)

6. 6. Y.C. Hu, and C.J. Chen, Information Sciences 181,4959-4968. (2011)

7. S. Murat, H. Kazan, and S. Coskun, Procedia Social and Behavioral Sciences $195729-738$ (2015)

8. V. Balali, B. Zahraie, A. Roozbahani, American Journal of Civil Engineering and Architecture, Vol. 2, No. 5, 149-159 (2014)

9. M. Muktiali, Riptek, Vol.3, No.2, Hal.: 11 - 20 (2009)

10. H.S. Oluwatosin, IOSR Journal of Computer Engineering (IOSR-JCE, -ISSN: 2278-0661, pISSN: 2278-8727, Volume 16, Issue 1, Ver. IX), PP 67-71) (2014)

11. S.C. Deshmukh, International Journal of Engineering Science Invention, www.ijesi.org Volume 2 Issue 11 PP.28-34 (2013) 